\title{
Variability levels of selected amino acids among mandarins produced in Uruguay
}

Sofía Rezende ${ }^{1,2} \oplus^{\infty}$, Sabrina Banchero ${ }^{2} \oplus$, Ignacio Migues $^{3} \oplus$, María Veronica Cesio $^{3} \oplus$, Carlos Fernando Rivas $^{4}{ }^{\oplus}$, Horacio Heinzen ${ }^{3}{ }^{\infty}$, María Natalia Besil ${ }^{1+}{ }^{+\infty}$

1. University of the Republic of Uruguay, Chemistry Department of Litoral, Paysandú, Uruguay.

2. Technological University, Southwest Regional Technological Institute, Paysandú, Uruguay.

3. University of the Republic of Uruguay, Faculty of Chemistry, Montevideo, Uruguay.

4. National Institute for Agricultural Research, Salto, Uruguay.

+Corresponding author: María Natalia Besil, Phone: +598-4722-7950, Email address: nbesil@fq.edu.uy

\section{ARTICLE INFO}

Article history:

Received: July 27, 2020

Accepted: July 16, 2021

Published: October 01, 2021

Section Editor: Assis Vicente Benedetti

\section{Keywords}

1. mandarins

2. amino acids

3. nutraceuticals

4. high performance liquid chromatography-mass spectrometry

ABSTRACT: Nutraceutical properties of mandarins are of great interest to promote their consumption. The occurrence of free amino acids in foods is relevant to assess the nutritional value of it. To learn more about the amino acids' occurrence and variability between species, a targeted metabolomics study in 'Ellendale', 'Willowleaf' and 'Page' varieties was performed through ion exchange liquid chromatography coupled to tandem mass spectrometry. The studied amino acids were

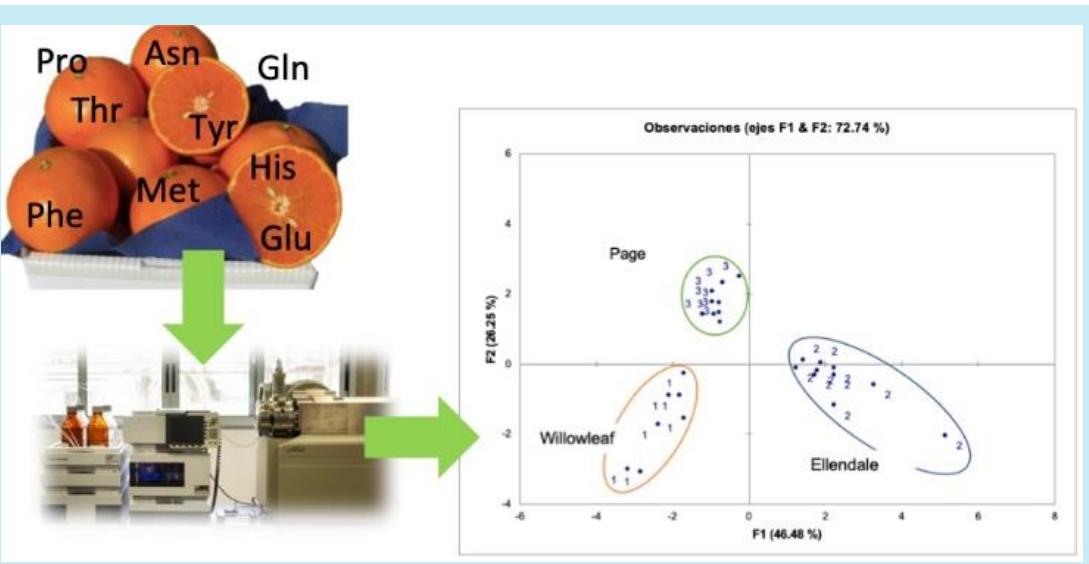
asparagine, glutamic acid, glutamine, histidine, methionine, phenylalanine, proline, threonine and tyrosine. The difference between two consecutive seasons was evaluated, as well as the influence of fruit maturity of 'Page' collected in two periods of 2015. The analytical methodology was validated. The concentration of the compounds through principal component analysis, separated well apart the three cultivars in both harvests, showing a particular profile for each of them. When comparing mature and immature cultivar 'Page', the amino acids with higher levels in mature samples were histidine, asparagine, glutamine and glutamic acid. The profiles were different due to genetic diversity, and the climatic conditions. These results add value to citric production. 


\section{Introduction}

In recent years, the consumption of healthy foods by the world population has been increasing. The knowledge on food composition seeking a healthier life boosts consumer demand for foods with low amounts of additives, fewer colorants, nontransgenic, with beneficial health properties beyond their own nutritional capacity (Fernández, 2007).

Particularly, citrus fruits contain nutritious ingredients and their consumption is associated with a reduction in the risk of cardiovascular diseases, diabetes and cancer, linked to the presence of flavonoids among other compounds with antioxidant and anti-inflammatory activity (Khan et al., 2014; Xi et al., 2014). Nevertheless, the presence and contribution of amino acids to the healthy properties of citrus fruits has not been acknowledged in recent reviews (Lado et al., 2018). It is reported that the amino acids present in different foods are used as nutraceuticals for the treatment and prevention of diseases (Sharma et al., 2016). It is also known that amino acids are essential nutrients in the diet and supplements containing them can be beneficial in strict vegetarian people. Recent studies suggest that a supplementation of tryptophan could improve the therapeutic treatment of patients with anorexia nervosa (Haleem, 2017). Besides, the supplements containing essential amino acids together with keto acids is beneficial to ensure an adequate supply of essential amino acids in patients with chronic kidney disease (Cupisti and Bolasco, 2017).

Particularly, mandarins have eight of the nine essential amino acids (histidine, isoleucine, leucine, lysine, methionine, phenylalanine, threonine, tryptophan and valine), which makes their consumption beneficial to human health, but the content of free amino acids is different depending on the variety. The total content of amino acids in Satsuma mandarin has been reported as $15 \mu \mathrm{mol} \mathrm{g} \mathrm{g}^{-1}$, being the most abundant ones aspargine $\left(3.5 \mu \mathrm{mol} \mathrm{g}^{-1}\right)$, arginine $\left(2.4 \mu \mathrm{mol} \mathrm{g}^{-1}\right)$, aspartic acid $\left(2.0 \mu \mathrm{mol} \mathrm{g}^{-1}\right)$, proline $\left(1.5 \mu \mathrm{mol} \mathrm{g} \mathrm{g}^{-1}\right)$ and glutamine $\left(1.0 \mu \mathrm{mol} \mathrm{g}^{-1}\right)$. Meanwhile, the remaining amino acids are in concentrations lower than $1 \mu \mathrm{mol} \mathrm{g} \mathrm{g}^{-1}$. Besides, in mandarin juices the most abundant amino acids are proline $\left(1 \mathrm{mg} \mathrm{mL} \mathrm{mL}^{-1}\right)$, arginine $\left(0.85 \mathrm{mg} \mathrm{mL}^{-1}\right)$, asparagine $\left(0.18-0.86 \mathrm{mg} \mathrm{mL}^{-1}\right)$, aspartic acid $(0.24-$ $0.50 \mathrm{mg} \mathrm{mL}-1)$, glutamic acid $\left(0.17-0.34 \mathrm{mg} \mathrm{mL}^{-1}\right)$, serine $\left(0.12-0.26 \mathrm{mg} \mathrm{mL}^{-1}\right)$, alanine and phenylalanine (0.60-0.15 mg mL $\left.\mathrm{mL}^{-1}\right)$. The total content of free amino acids changes during the maturity of the fruit, being proline and arginine those that showed the most substantial changes (Ladanyia, 2008). In citrus fruits, free amino acids play an important role as osmoprotectants, but also their connection to disease resistance had been highlighted (Killiny and Hijaz, 2016; Sadka et al., 2019). Although amino acids are compounds which belong to the primary metabolism, their contribution to specific adaptive properties to stress places them as contributors to the role of secondary metabolism. Secondary metabolites are normally at concentration levels of one or two orders of magnitude lower than primary metabolites. Given the reported amounts of amino acids in citrus fruits, it could be of interest to study the changes they go through between two different cropping years, with distinct water availability during fruit development. To study these changes, coupling analytical determinations with statistical analyses is the most appropriate strategy (Dewick, 2009). Within this frame, the study of changes in the amino acids profile, using the concepts of targeted metabolomics was faced using liquid chromatography-tandem mass spectrometry. Up to date, there have not been studies using a targeted determination by ion exchange liquid chromatographymass spectrometry (LC-(ESI)-MS/MS) of the occurrence of amino acids in mandarins produced in the region. These data allow the regional and national industries to characterize and differentiate their production from a nutraceutical point of view. With this idea in mind, the inter-cultivar composition variability of nine amino acids in cultivars Willowleaf, Page and Ellendale, as well as the variations between two consecutive harvests, is presented in this work.

\section{Materials and methods}

\subsection{Samples}

Mandarin samples were bred at Instituto Nacional de Investigación Agropecuaria (INIA) - Salto Grande $\left(31^{\circ} 16^{\prime} 18^{\prime \prime} \mathrm{S} 57^{\circ} 53^{\prime} 26^{\prime \prime} \mathrm{W}\right)$ in two consecutive harvesting seasons during 2015 and 2016. Fruits were harvested at their optimal fruit ripening and stored at $20{ }^{\circ} \mathrm{C}$ until processed.

A total of 59 samples of mandarins of three different genetically stable cultivars: Willowleaf (Citrus reticulata), Page (Tangelo minneola $\times$ Clementina), Ellendale (Citrus sinensis $\times$ Citrus reticulata) were selected for this study. In the sampling process, 10 mandarins were taken from each tree randomly. At the time of harvest, the quality parameters of the fruit (titratable acidity, soluble solids, texture, internal and external color) were evaluated to ensure that the maturity between the varieties was the 
same. In the case of 'Page' (2015), the samplings were carried out in May and July in order to evaluate the amino acids profile for the same variety at different maturity stages.

\subsection{Reagents and materials}

High purity amino acid standards were provided by Sigma-Aldrich. Individual standard solutions were prepared at a concentration of $1000 \mathrm{mg} \mathrm{L}^{-1}$, using a mixture of $50: 50 \quad \mathrm{CH}_{3} \mathrm{OH}: \mathrm{H}_{2} \mathrm{O} \quad 0.1 \%$ formic acid $(\mathrm{HCOOH})$ as solvents. Subsequently, a mix of $10 \mathrm{mg} \mathrm{L}^{-1}$ was prepared, containing all the purchased amino acids, making the corresponding dilutions from the different standard solutions. Ultra-pure water was used as solvent for the mobile phase and acidified water with $1 \mathrm{mmol} \mathrm{L} \mathrm{L}^{-1}$ citric acid (Analar-BDH Chemical Ltd Poole England) and finally adjusted to $\mathrm{pH} 11$ with dimethylamine (DMA). Methanol (PHARMCO-AAPER) quality UV-HPLC and chloroform (J.T. Baker) quality HPLC were used as extraction solvents.

For the extraction procedure, $50 \mathrm{~mL}$ conical polypropylene tubes, $5 \mathrm{~mL}$ syringes and $0.45 \mu \mathrm{m}$ hydrophobic PTFE filters were used. Vials of 12 and $4 \mathrm{~mL}$ to store the samples, and vials for automatic sampling of $2 \mathrm{~mL}$ with screw cap and septum for injection in the chromatographic equipment were used.

\subsection{Apparatus and experimental conditions}

The LC-(ESI)-MS/MS analysis was performed with an Agilent 1200 LC system (Agilent Technologies, Palo alto, CA, USA) coupled to a 4000 QTRAP LCMS/MS system from AB SCIEX ${ }^{\mathrm{TM}}$ (Framingham, Massachusetts, USA) run in the Scheduled MS/MSmode. The LC-Separation was performed on a Dionex AS11 $(250 \times 2 \mathrm{~mm}, 4 \mu \mathrm{m})$ ion exchange column. The column temperature was $40^{\circ} \mathrm{C}$ and it was reconstituted after de analysis with a solution of $\mathrm{NaOH} 30 \mathrm{mmol} \mathrm{L}^{-1}$. The operation of the LC gradient involved the elution program described in Fig. 1, A: water; B: water $1 \mathrm{mmol} \mathrm{L}{ }^{-1}$ citric acid and adjusted to $\mathrm{pH} 11$. It was run at $300 \mu \mathrm{L} \mathrm{min}{ }^{-1}$. The injection volume was $5 \mu \mathrm{L}$. The MS/MS detection was performed with a QqQ analyzer in the multiple reaction monitoring (MRM) mode using an Electrospray Ionization (ESI) interface in the negative ion mode (Bringans et al., 2011). The ionization voltage was $5000 \mathrm{~V}$, the nebulizer and the curtain gases were nitrogen at $50 \mathrm{psi}$ each. The solvent evaporation in the source was assisted by a drying gas (heated nitrogen at $500{ }^{\circ} \mathrm{C}$ per $50 \mathrm{psi}$ ). The optimal
MRM transitions, collision energies (CE), cell exit potential (CXP) and declustering potentials (DP) for each investigated compound were determined infusing with a syringe directly the amino acids individual standard solutions to the instrument at a constant flow of $10 \mu \mathrm{L} \mathrm{min}{ }^{-1}$.

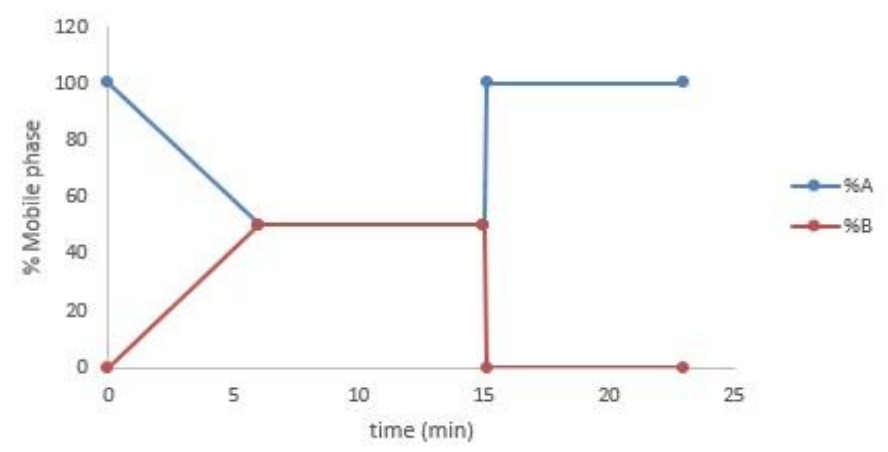

Figure 1. LC-MS/MS elution program.

\subsection{Instrumental identification}

The criteria used for identification of the targeted analytes using MRM acquisition mode, based in mass spectrometry pesticide residue analysis guidelines, were retention time of the analyte corresponding to that of the calibration standard ( $0.1 \mathrm{~min}$ of tolerance) and the precursor ion that yields product ions of specific $\mathrm{m} / \mathrm{z}$., called transitions. Additional confirmation was achieved evaluating the reference ion ratio. The reference ion ratio $(\mathrm{m} / \mathrm{z}$ ratio) is the average obtained in solvent of standards measured in the same sequence and under the same conditions as the samples $\left[\operatorname{Intensity}(\mathrm{m} / \mathrm{z})_{\text {transition }} /\left(\right.\right.$ intensity $\left.\left.(\mathrm{m} / \mathrm{z})_{\text {parent }}\right)\right]$. The MRM transitions ratio from sample extracts should be within $\pm 30 \%$ (relative) of average of calibration standards tolerance deviation (EURL, 2017).

\subsection{Amino acids extraction}

The amino acids were extracted from mandarins pulp with a methodology adapted from Verpoorte et al. (2007). For the extraction of the amino acids, $2.0 \pm$ $0.1 \mathrm{~g}$ of frozen crushed pulp were placed in a $50 \mathrm{~mL}$ polypropylene centrifuge tube together with $8 \mathrm{~mL}$ of $\mathrm{CHCl}_{3}$ (LiChrosolv, Merck, Germany), $4 \mathrm{~mL}$ of $\mathrm{MeOH}$ (LiChrosolv, Merck, Germany), and $4 \mathrm{~mL}$ of ultrapure water (Millipore Milli-Q Ultrapure Water Solutions Type 1). The resulting suspension was vortexed for $30 \mathrm{~s}$ and sonicated for $60 \mathrm{~s}$. It was then centrifuged for $5 \mathrm{~min}$ at $1400 \mathrm{xg}$, the phases were separated, and $8 \mathrm{~mL}$ of $\mathrm{CHCl}_{3}$ were added to the aqueous phase. The whole 
process was repeated, and the organic phases were combined and stored for future analysis. The aqueous extract was filtered, distilled under reduced pressure to remove $\mathrm{MeOH}$, and then lyophilized to remove water (Migues et al., 2021). Finally, the freeze-dried extract was dissolved in water and citric acid adjusted to $\mathrm{pH} 11$ with DMA, filtered and placed in a $2 \mathrm{~mL}$ injection vial.

\subsection{Study of linearity and limit of quantification (LOQ)}

The LOQ and linearity were determined from the calibration curves performed in solvent for each analyte. To establish the linear range, curves that have a correlation coefficient greater than 0.99 and a good visual adjustment were considered acceptable. The LOQ was determined by the lowest level of concentration studied in which a signal-to-noise ratio greater than 10 was obtained and an adequate peak shape with correct superposition between transitions was observed.

\subsection{Statistical analysis}

For data treatment, the XLSTAT version 2015 software was used, as well as the principal component analysis (PCA) and Levene's test for homogeneity of variances.

A student's t test was applied to the results obtained for two samples, assuming equal variances with $95 \%$ confidence. This test assumes normal distribution and homogeneity of variances between the samples. For the samples that did not present homogeneous variances, a student's test was performed for two samples with unequal variances.
For the classification of mandarin varieties, to evaluate their diversity, and to identify outliers within each class, PCA was employed. For the identification of the most relevant amino acids between harvests, a discriminant analysis of partial least squares (PLS-DA) was performed using MetaboAnalyst software (version 4.0) (Chong et al., 2018; Chong and Xia, 2018). Pareto scaling was applied to minimize the weight of large values while maintaining data structure partially intact (van den Berg et al., 2006). The models derived from PLS-DA were validated using permutation tests of 100 iterations where the classes were randomly reassigned, two thirds of the data were used as training data to build a classifier, and the remaining third of the data was used to test it. The VIP scores study based on loadings from the PLS analysis show the amino acid that contribute to the separation and differentiation of the two harvests.

\section{Results and discussion}

The production of mandarins in Uruguay has a broad harvest calendar that covers from the end of February (mid-summer) to the end of October (midspring) according to the different varieties that are cultivated. These numerous varieties have been originated by spontaneous mutations of mandarins or by crossing with other citrus fruits, such as orange or grapefruit (Otero et al., 2020). Differences in their amino acids profiles are expected due to their wide genetic variety and harvesting times during the year (Kefford and Chandler, 1970; Underwood and Rockland, 1953). The amino acids selected for the study, listed in Tab. 1, represent a combination of essential amino acids and those with relevant osmoprotective properties.

Table 1. Mass of the ions generated operating in ESI negative mode. Amino acid, precursor ion and product ( $\mathrm{m} \mathrm{Z}^{-1}$ ), fragmentation potential (DP), collision energy (CE), input potential (EP), cell output potential (CXP) is from the mass analyzer operating in ESI mode negative.

\begin{tabular}{|l|c|c|c|c|c|c|}
\hline Amino acid & $\begin{array}{c}\text { Precursor ion } \\
\left(\mathbf{m ~ Z}^{-\mathbf{1}}\right)\end{array}$ & $\begin{array}{c}\text { Product ion } \\
\left(\mathbf{m ~ Z}^{-\mathbf{1}}\right)\end{array}$ & $\mathbf{D P}(\mathbf{V})$ & $\mathbf{E P}(\mathbf{V})$ & $\mathbf{C E}(\mathbf{V})$ & $\mathbf{C X P}(\mathbf{V})$ \\
\hline \multirow{3}{*}{ Asparagine } & 132.0 & 88.0 & -10 & -10 & -16 & -8 \\
\cline { 2 - 7 } & 132.0 & 115.0 & -10 & -10 & -16 & -10 \\
\hline Glutamine & 132.0 & 71.0 & -10 & -10 & -18 & -6 \\
\hline Methionine & 145.0 & 128.0 & -10 & -10 & -12 & -6 \\
\hline \multirow{3}{*}{ Phenylalanine } & 148.0 & 47.0 & -10 & -10 & -22 & -6 \\
& 164.0 & 147.0 & -70 & -10 & -18 & -25 \\
\cline { 2 - 7 } & 164.0 & 103.0 & -70 & -10 & -24 & -15 \\
\cline { 2 - 7 } & 164.0 & 72.0 & -70 & -10 & -20 & -11 \\
\hline
\end{tabular}




\begin{tabular}{|l|c|c|c|c|c|c|}
\hline \multirow{2}{*}{ Tyrosine } & 180.0 & 163.0 & -80 & -10 & -20 & -27 \\
\cline { 2 - 7 } Threonine & 180.0 & 119.0 & -80 & -10 & -26 & -19 \\
\cline { 2 - 7 } & 118.0 & 74.0 & -55 & -10 & -14 & -11 \\
\hline \multirow{2}{*}{ Proline } & 118.0 & 72.0 & -55 & -10 & -18 & -11 \\
\hline \multirow{3}{*}{ Histidine } & 114.0 & 68.0 & -75 & -10 & -10 & -17 \\
\cline { 2 - 7 } & 114.0 & 66.0 & -75 & -10 & -26 & -13 \\
\hline \multirow{2}{*}{ Glutamic acid } & 154.0 & 109.0 & -40 & -10 & -20 & -10 \\
& 154.0 & 93.0 & -40 & -10 & -10 & -10 \\
\end{tabular}

\subsection{Targeted analysis}

Taking into account that the level of the concentrations of free amino acids reported in mandarins are in the order of $\mu \mathrm{g} / \mathrm{kg}$, as well as the polarity of the moieties, the most suitable analytical approach for their analysis is liquid chromatography coupled to mass spectrometry. Due to the ionic behavior of these compounds, the use of the reverse phase in liquid chromatography (LC) is not the best selection for the analysis. The reported methods show that it is possible to analyze them directly, using an ion exchange column (Piraud et al., 2003), polar columns (Yao et al., 2013), or indirectly, using derivatization (Alterman and Hunziker, 2012). Particularly, in this work the analysis was performed using an ion exchange column, as it is described in section 2.3, to avoid the standardization of the derivative reaction and make the analysis simpler.

For the analysis it was necessary to optimize the chromatographic separation with an ion exchange column (Fig. 2), as well as the tandem mass detector conditions described above (Tab. 1).

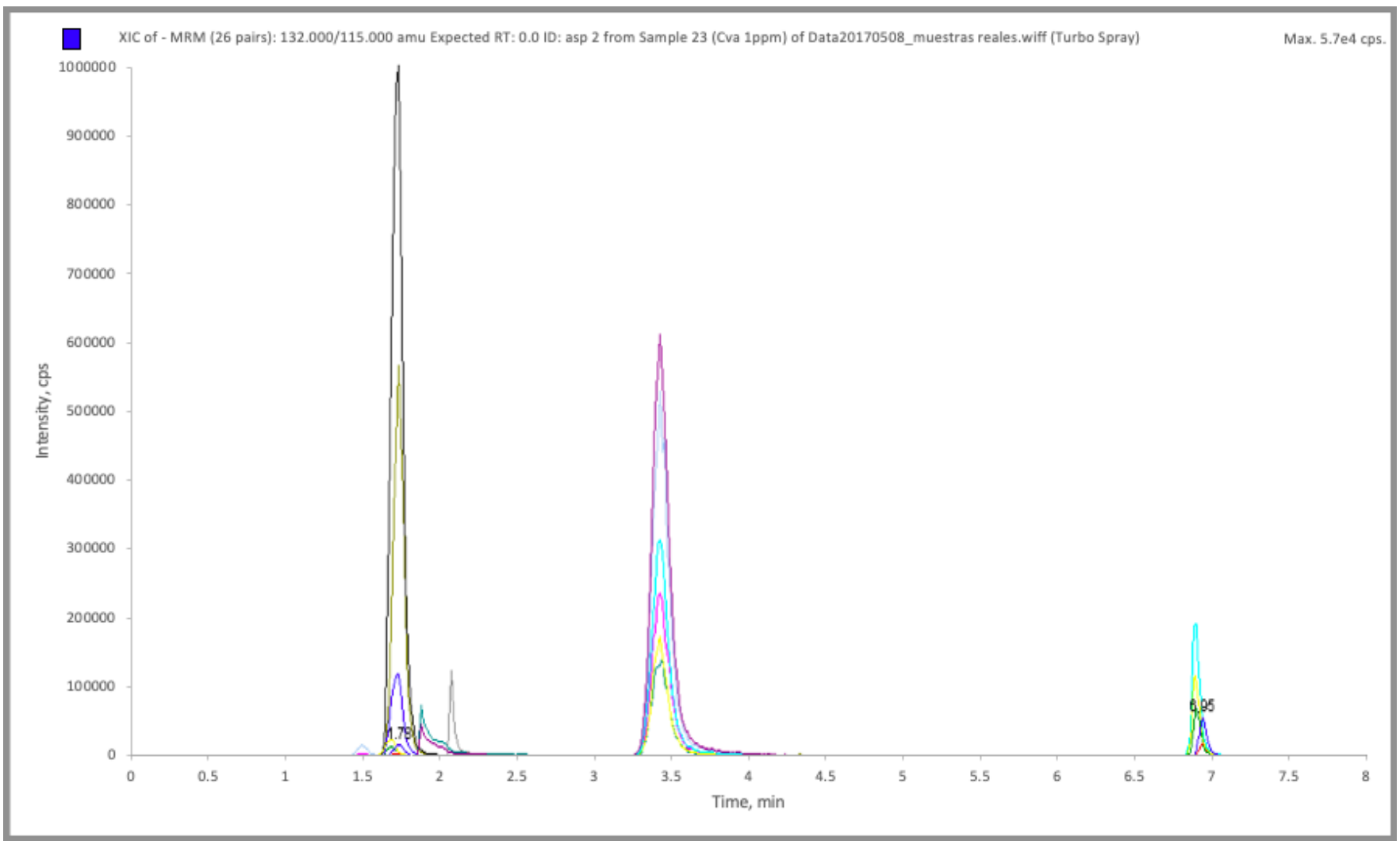

Figure 2. Multi reaction monitoring (MRM) chromatogram of the nine studied amino acids at a $1 \mathrm{mg} \mathrm{L}^{-1}$ level.

The final instrumental method was based on the MRM operation mode, which is a highly specific and sensitive mass spectrometry operation mode that can selectively quantify compounds in a complex matrix 
(Bringans et al., 2011; Wright et al., 2015). Multiple reaction monitoring provides high selectivity to the determination, enhancing the signal to noise $(\mathrm{S} / \mathrm{N})$ ratio of the peaks, improving the overall sensitivity.

In summary, the triple quadrupole configuration allows to work in tandem mass spectrometry configuration. The first quadrupole acts as a filter for the $[\mathrm{M}-\mathrm{H}]^{-}$ions generated in the ESI source, they are then guided to a second quadrupole which is a collision chamber. The $[\mathrm{M}-\mathrm{H}]^{-}$ions (precursor ion) degrade to fragmented ions (product ions). The third quadrupole filters the product ions, eliminating the back noise that spoils the $\mathrm{S} / \mathrm{N}$ relationship. The transitions from the precursor ion to the product ion are highly specific and are the basis for the high selectivity and sensibility of the MRM acquisition mode. In this work, precursor ions, declustering potential, product ions, cell exit potential and collision energies were determined by direct infusion of each analyte. It is important to notice that, for each precursor ion, different collision energies and cell exit potential are settled in order to enhance the production of each product ion and, as a consequence, a better $\mathrm{S} / \mathrm{N}$ ratio will be obtained.

For MRM compounds optimization and MRM quantitative analysis, amino acids standards are necessary. Focused on the instrumental confirmation of the analytes, two transitions were monitored, and a time-scheduled acquisition method was developed. However, this criterion has not been accomplished for glutamine and methionine, it was only possible to optimize just one transition for each of these compounds.

\subsection{Linearity and $L O Q$}

The linearity was evaluated with calibration curves in solvent in a range between $5-1000 \mu \mathrm{g} \mathrm{L}^{-1}$. For all the amino acids in study a linear adjustment was obtained with a correlation coefficient higher than 0.99 in a range that varies with the analyzed compound. The linear ranges for each compound were set from the LOQ value to $1000 \mu \mathrm{g} \mathrm{L}^{-1}$.

The LOQs obtained were $10 \mu \mathrm{g} \mathrm{L}^{-1}$ for asparagine, methionine and threonine, $20 \mu \mathrm{g} \mathrm{L}^{-1}$ for phenylalanine and glutamic acid, $50 \mu \mathrm{g} \mathrm{L}^{-1}$ for histidine, $100 \mu \mathrm{g} \mathrm{L}^{-1}$ for glutamine, $250 \mu \mathrm{g} \mathrm{L}^{-1}$ for tyrosine and $500 \mu \mathrm{g} \mathrm{L}^{-1}$ for proline, respectively.

\subsection{Sample analysis}

A total of 59 mandarin samples were analyzed (33 belonging to the 2015 harvest and 26 to the 2016 harvest). The samples from 2015 were: 10 cultivar Ellendale, 13 cultivar Page and 10 cultivar Willowleaf. While the ones from 2016 were: 10 cultivar Ellendale, 9 cultivar Page and 7 cultivar Willowleaf.

To study the variability of the amino acids content during maturation of cultivar Page, a total of 23 samples collected in May and July of 2015 were tested.

The content of each amino acid (expressed as $\mu \mathrm{g} \mathrm{g}^{-1}$ of dried extract) present in the different varieties in two years of production are presented in Tabs. 2 and 3. The amino acids were distributed in a wide range of concentration as it was reported by Ladanyia (2008). The amino acid with higher concentration was a different one in the three studied varieties. Ellendale presented proline, as the amino acid with higher concentration in both years of production studied, while 'Willowleaf' was characterized by the presence of asparagine and for cultivar Page the prevalent ones were proline and asparagine in both harvests, being the concentration level of glutamic acid remarkably close to the levels of the other two.

Table 2. Average, maximum and minimum concentrations of the nine amino acids for the three varieties year 2015.

\begin{tabular}{|c|c|c|c|c|c|c|c|c|c|}
\hline Harvest 2015 & \multicolumn{3}{|c|}{ 'Willowleaf' } & \multicolumn{3}{|c|}{ 'Ellendale' } & \multicolumn{3}{|c|}{ 'Page' } \\
\hline $\begin{array}{l}\text { Concentration } \\
\left(\mu \mathrm{g} \mathrm{g}^{-1}\right)\end{array}$ & Average & Minimum & Maximum & Average & Minimum & Maximum & Average & Minimum & Maximum \\
\hline Glutamic acid & 266.0 & 240.0 & 500.0 & 163.0 & 89.0 & 305.0 & 577.1 & 358.9 & 1360.6 \\
\hline Asparagine & 1215.7 & 40.0 & 4560.0 & 2021.4 & 811.0 & 3556.0 & 806.4 & 66.0 & 1369.0 \\
\hline Phenylalanine & 26.2 & 16.0 & 35.0 & 196.1 & 89.0 & 254.0 & 46.0 & 12,0 & 92.0 \\
\hline Glutamine & 665.8 & 18.0 & 2593.0 & 200.6 & 101.0 & 362.0 & 55.9 & 10.0 & 86.0 \\
\hline Histidine & $<\mathrm{LOQ}$ & $<\mathrm{LOQ}$ & $<\mathrm{LOQ}$ & 33.8 & 26.0 & 61.0 & $<\mathrm{LOQ}$ & $<\mathrm{LOQ}$ & $<\mathrm{LOQ}$ \\
\hline Methionine & $<$ LOQ & $<\mathrm{LOQ}$ & $<\mathrm{LOQ}$ & $<\mathrm{LOQ}$ & $<\mathrm{LOQ}$ & $<\mathrm{LOQ}$ & $<\mathrm{LOQ}$ & $<\mathrm{LOQ}$ & $<\mathrm{LOQ}$ \\
\hline Proline & 6.7 & 1.0 & 11.0 & 7431.0 & 330.6 & 11615.5 & 996.9 & 641.2 & 1440.2 \\
\hline Tyrosine & $<\mathrm{LOQ}$ & $<\mathrm{LOQ}$ & $<\mathrm{LOQ}$ & 77.9 & 37.0 & 111.0 & 11.3 & 6.0 & 20.0 \\
\hline Threonine & 15.8 & 7.0 & 35.0 & 84.8 & 45.0 & 114.0 & 16.2 & 9.0 & 38.0 \\
\hline
\end{tabular}


Table 3. Average, maximum and minimum concentrations of the nine amino acids for the three varieties year 2016.

\begin{tabular}{|c|c|c|c|c|c|c|c|c|c|}
\hline Harvest 2016 & \multicolumn{3}{|c|}{ 'Willowleaf' } & \multicolumn{3}{|c|}{ 'Ellendale' } & \multicolumn{3}{|c|}{ 'Page' } \\
\hline $\begin{array}{l}\text { Concentration } \\
\left(\mu \mathrm{g} \mathrm{g}^{-1}\right)\end{array}$ & Average & Minimum & Maximum & Average & Minimum & Maximum & Average & Minimum & Maximum \\
\hline Glutamic acid & 348.1 & 51.0 & 963.0 & 280.0 & 195.0 & 346.0 & 1457.4 & 865.0 & 1969.3 \\
\hline Asparagine & 5629.2 & 3148.0 & 8044.0 & 1377.1 & 517.0 & 2769.0 & 2255.5 & 1128.3 & 2985.2 \\
\hline Phenylalanine & 60.1 & 39.0 & 76.0 & 130.0 & 81.0 & 264.0 & 83.6 & 69.4 & 99.4 \\
\hline Glutamine & 340.9 & 114.0 & 570.0 & 231.7 & 66.0 & 689.0 & 148.5 & 103.0 & 231.0 \\
\hline Histidine & $<\mathrm{LOQ}$ & $<$ LOQ & $<$ LOQ & 68.2 & 40.0 & 127.0 & 19.8 & 10.0 & 33.0 \\
\hline Methionine & 2.0 & 1.0 & 3.0 & $<\mathrm{LOQ}$ & $<\mathrm{LOQ}$ & $<$ LOQ & $<\mathrm{LOQ}$ & $<$ LOQ & $<$ LOQ \\
\hline Proline & 18.6 & 13.0 & 24.0 & 4293.6 & 3055.0 & 5627.0 & 1601.1 & 634.0 & 3429.0 \\
\hline Tyrosine & $<\mathrm{LOQ}$ & $<$ LOQ & $<$ LOQ & $<$ LOQ & $<\mathrm{LOQ}$ & $<$ LOQ & 43.0 & 24.0 & 96.0 \\
\hline Threonine & 3.1 & 2.0 & 5.0 & 97.4 & 67.0 & 146.0 & 26.3 & 19.0 & 45.0 \\
\hline
\end{tabular}

In general, asparagine showed a wide range of concentrations among all the varieties. Low concentration levels of threonine, methionine and tyrosine were observed in the three varieties. Moreover, low concentrations ranges were observed for these amino acids in both evaluated years.

For 'Willowleaf' it was only possible to identify but not to quantify histidine and tyrosine because they concentration levels were below the LOQs. Same scenario was seen for asparagine, glutamine, threonine and methionine in 'Ellendale'; and for 'Page', methionine was not detected in neither of the studied years of production.

These results are in line with previous literature reports which assigned the variability in the mandarins amino acids composition to their wide genetic variety and their harvest time during the year (Otero et al., 2020; Underwood and Rockland, 1953).

\subsection{Statistical analysis}

A student's t-test was carried out to study if the amino acid profiles were the same in each variety in the harvest of 2015 and 2016. The results for 'Willowleaf' variety showed that the concentrations of the amino acids asparagine, phenylalanine and proline have significant differences, while glutamine, methionine and glutamic acid have no significant differences.

Cultivar Ellendale showed that glutamic acid, phenylalanine, histidine, tyrosine and proline presented significant differences between their concentrations.

For cultivar Page, it was observed that glutamic acid, asparagine, phenylalanine, glutamine, proline, tyrosine and threonine present significant differences, while histidine did not present significant differences.
The student's t-test was also carried out for 'Page' harvested in May and July 2015 to study the differences in the amino acid profiles due to ripening. The results show that there are no significant differences between the concentration levels of the amino acids: glutamic acid, asparagine, phenylalanine, tyrosine and threonine. However, significant differences were observed for glutamine, histidine and proline. The difference between the amino acids? profiles can be explained by the influence of several factors, such as genetic, maturity, the position of the fruit in the tree, management of the plant, climatic conditions and field factors (Otero et al., 2020; Underwood and Rockland, 1953). The differences in appearance and taste that distinguish the different types and varieties of citrus are fundamentally differences in chemical composition because of genetic factors (Underwood and Rockland, 1953).

After the evaluation of the amino acid profiles in each mandarin variety, a PCA was carried out to study the differentiation of these varieties due to their amino acids composition. The PCA was implemented separately for the 2015 and 2016 samples.

\subsubsection{Principal component analysis (PCA) of 2015 samples}

In the PCA carried out for the varieties harvested in 2015, a slight separation between samples was achieved. According to the concentration levels, cultivar Ellendale is characterized by the presence of threonine, histidine, proline, phenylalanine and tyrosine; the cultivar Page is distinguished by containing a high concentration of glutamic acid; while 'Willowleaf' mandarin is differentiated by its content of methionine and glutamine (Fig. 3). 


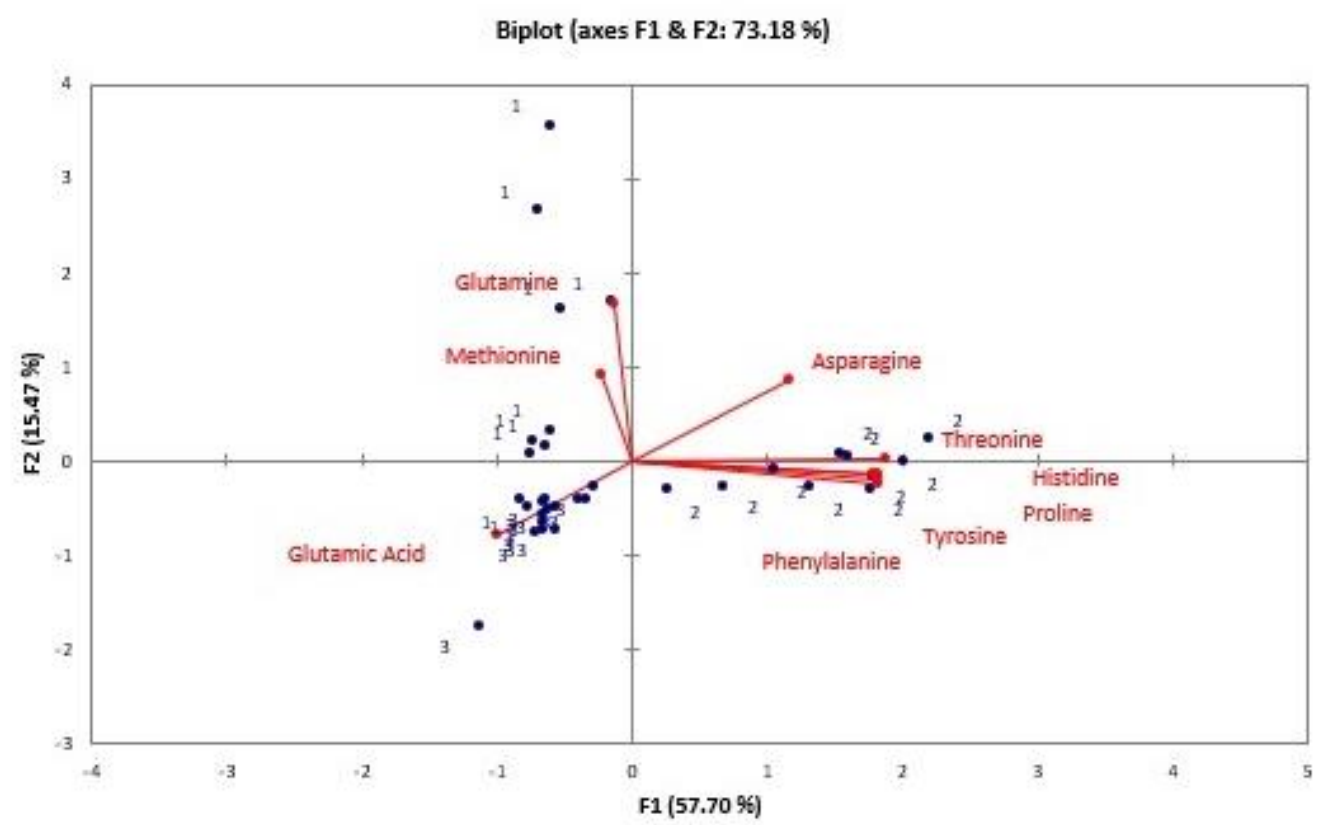

Figure 3. Principal component analysis of the three varieties of mandarin harvested in 2015 (1: 'Willowleaf'; 2 : 'Ellendale'; 3: 'Page').

3.4.2 Principal component analysis of 'Page' May-July 2015 samples

Page variety harvests were carried out in two periods of the same year, in May and July 2015, being able in this way to compare the amino acid profiles of the fruit depending on the ripening grade (Tab. 4). Lin et al., (2015) reported that the concentration of free amino acids may increase or decrease depending on the maturity of the fruit. In this study, it was observed that some amino acids content increased (glutamic acid, asparagine and phenylalanine) upon maturity. The level of proline slightly decreased and a possible explanation for this result is the well-known increment in sugars concentration upon maturation, which will also increase the osmotic pressure within the juice sacs and, therefore, the contribution of proline as osmoprotectant is no longer needed (Torres et al., 2007). The results of the PCA (Fig. 4) showed a differentiation between mandarins at different harvest times, being those of July better represented by the amino acids histidine, asparagine, glutamine and glutamic acid.

Table 4. Average, maximum and minimum concentrations of the nine amino acids for the variety 'Page' May-July 2015.

\begin{tabular}{|l|c|c|c|c|c|c|}
\hline Harvest $\mathbf{2 0 1 5}$ & \multicolumn{3}{|c|}{ 'Page' May } & \multicolumn{3}{c|}{ 'Page' July } \\
\hline Concentration $\left(\boldsymbol{\mu g ~ g}^{-\mathbf{1}}\right)$ & Average & Minimum & Maximum & Average & Minimum & Maximum \\
\hline Glutamic acid & 589.7 & 178.0 & 976.5 & 1457.4 & 865.0 & 1969.3 \\
\hline Asparagine & 2378.8 & 43.7 & 8378.3 & 2255.5 & 1128.3 & 2985.2 \\
\hline Phenylalanine & 45.8 & 30.6 & 74.0 & 83.6 & 69.4 & 99.4 \\
\hline Glutamine & 345.2 & 24.8 & 943.2 & 148.5 & 103.0 & 231.0 \\
\hline Histidine & 126.6 & 5.8 & 260.4 & 19.8 & 10.0 & 33.0 \\
\hline Methionine & $<$ LOQ & $<$ LOQ & $<$ LOQ & $<$ LOQ & $<$ LOQ & $<$ LOQ \\
\hline Proline & 1803.6 & 947.8 & 2947.9 & 1601.1 & 634.0 & 3429.0 \\
\hline Tyrosine & 14.7 & 3.7 & 20.3 & 43.0 & 24.0 & 96.0 \\
\hline Threonine & 19.5 & 1.7 & 24.6 & 26.3 & 19.0 & 45.0 \\
\hline
\end{tabular}




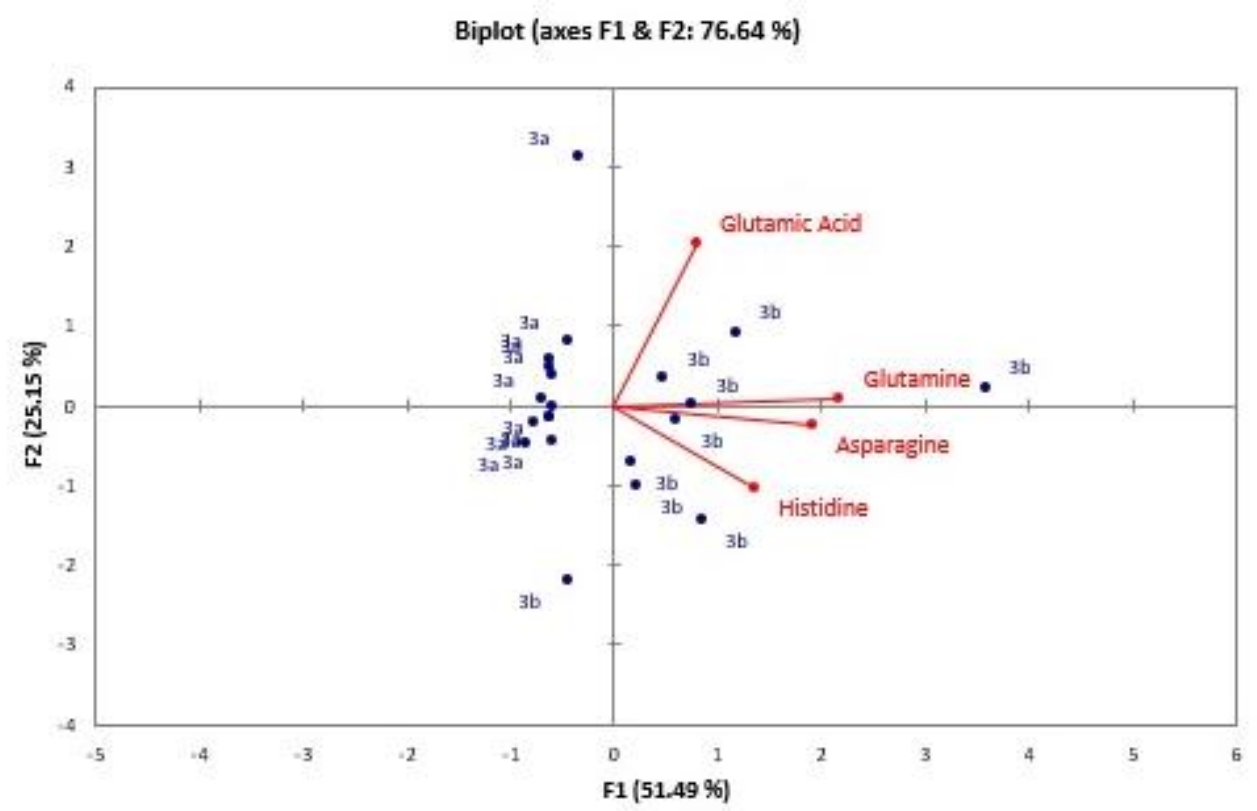

Figure 4. Principal component analysis of 'Page' variety with different degree of maturity (3a: May harvest; $3 \mathrm{~b}$ : July harvest).

\subsubsection{Principal component analysis of 2016 samples}

For the varieties harvested in 2016, there is a clear differentiation between the samples of the three cultivars Ellendale, Page and Willowleaf. 'Ellendale' was characterized for its high concentration levels of glutamine, phenylalanine, histidine and threonine; whereas cultivar Page is represented by its high content of glutamic acid and tyrosine; and asparagine and methionine were the major amino acids for cultivar Willowleaf samples (Fig. 5).

Biplot (axes F1 \& F2: 72.74 \%)

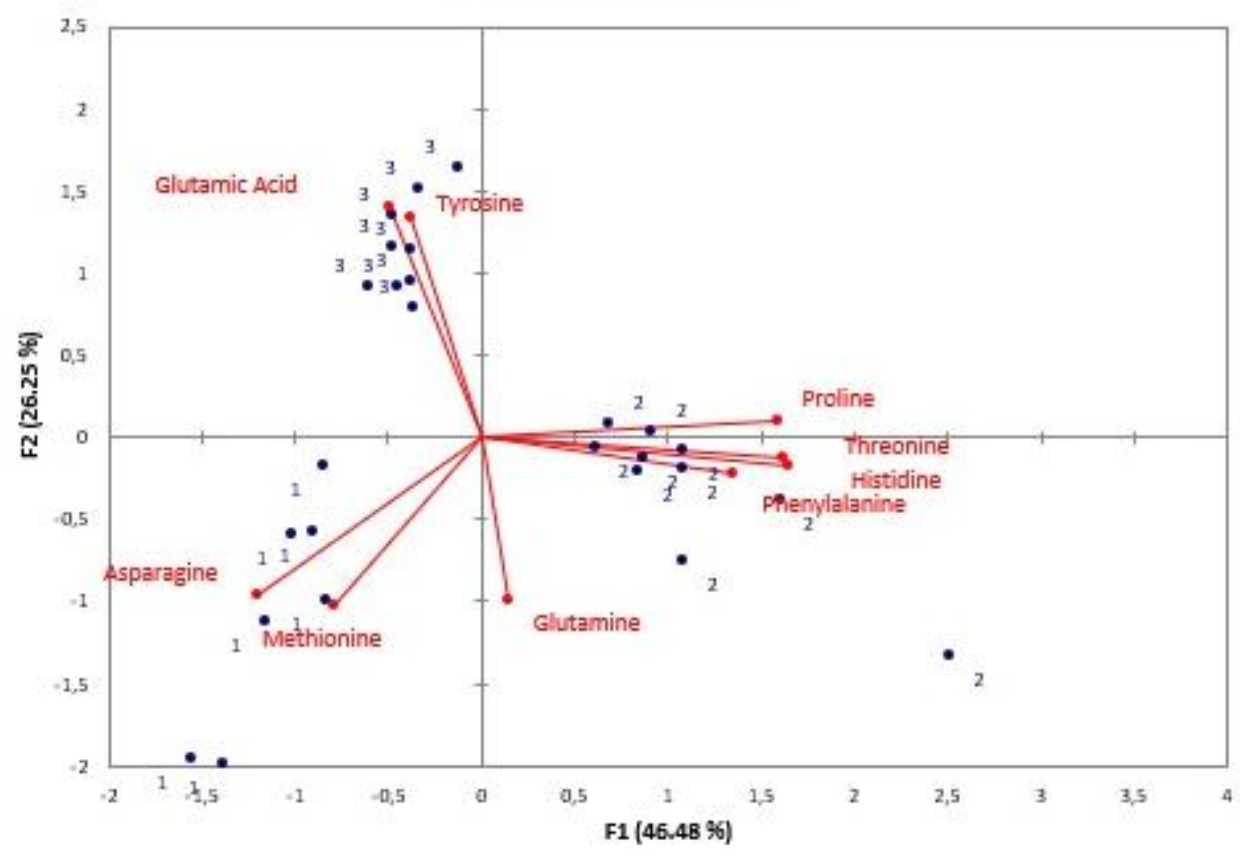

Figure 5. Principal component analysis of the three varieties of mandarin harvested in 2016 (1: 'Willowleaf'; 2: 'Ellendale'; 3: 'Page'). 
3.4.4 Discriminant analysis of partial least squares of the varieties harvested in 2015 and 2016

The comparison between Ellendale variety harvested in 2015 and 2016 indicate that the amino acid that weighted the most in the differentiation between both years is proline followed by asparagine (Fig. 6a). In Page variety, the most important amino acid for this classification was asparagine followed by glutamic acid and proline (Fig. 6b).
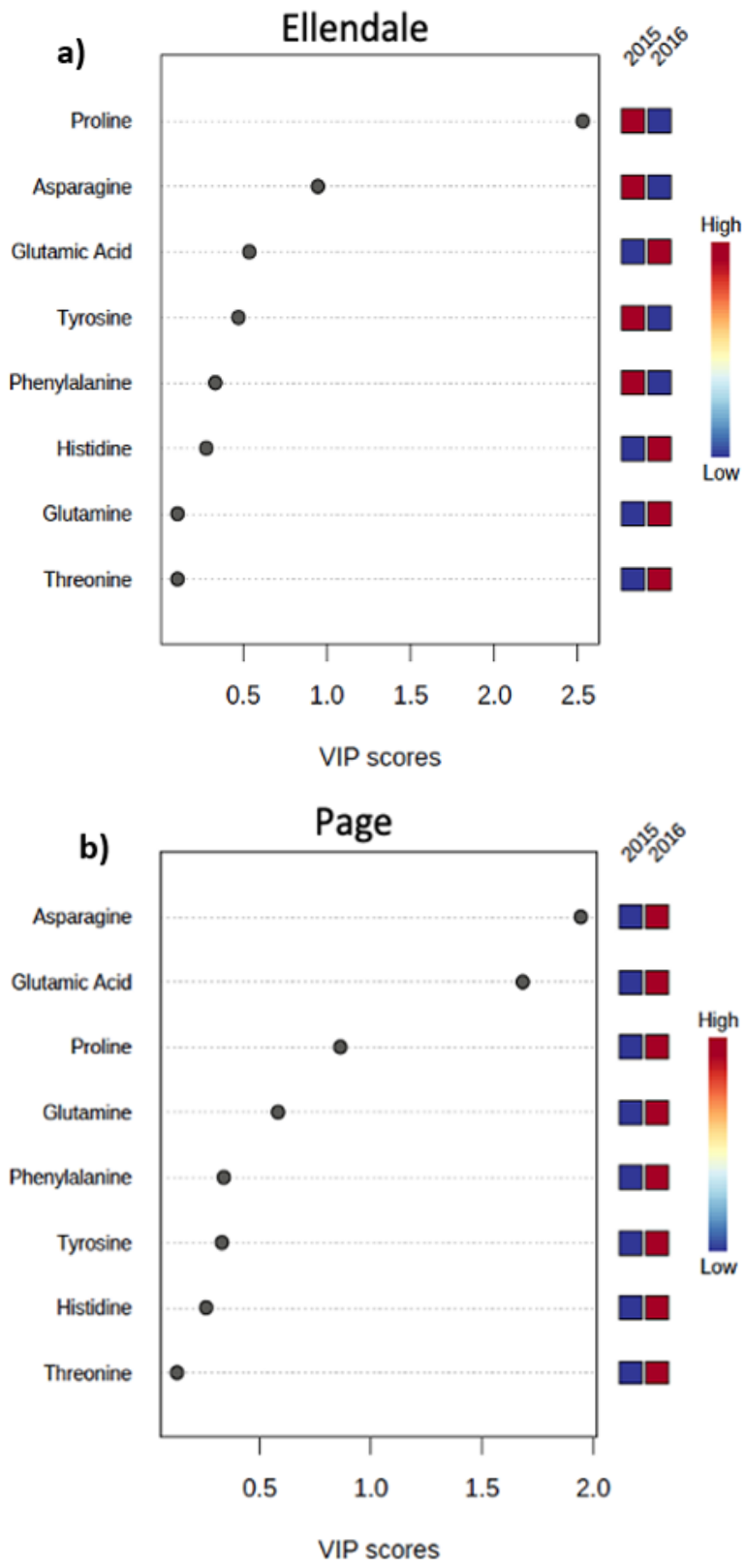

Figure 6. The VIP score plots of the PLS analysis performed on 'Ellendale' (a) and 'Page' (b) cultivated in 2015 and 2016.
In the case of 'Willowleaf' (Fig. 7a), asparagine was the amino acid that showed greater changes between harvests followed by glutamic acid and proline, the same was as in cultivar Page. When this analysis was performed with all the three samples together (Fig. 7b), the results also indicate asparagine, glutamic acid and proline as the amino acids that suffered the most drastic change between one harvest and the other.
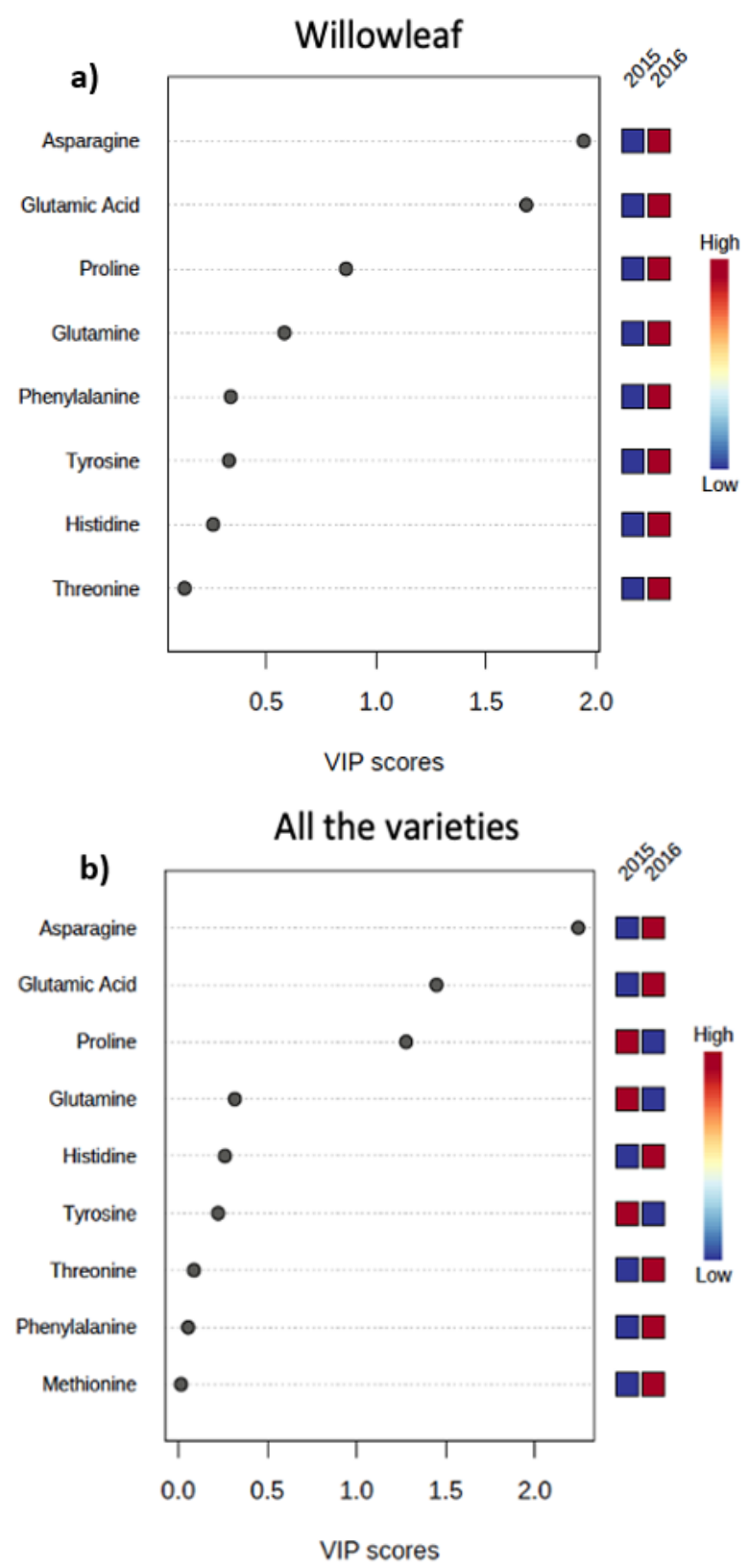

Figure 7. The VIP score plots of the PLS analysis performed on 'Willowleaf' (a) and the three varieties together (b) cultivated in 2015 and 2016. 
Even though the most abundant amino acid for each variety was the same between harvests (see section 3.2), this type of analysis allows to identify the most important concentration changes between one harvest and the other. These changes could also be attributed to environmental conditions during maturation process as 2016 was characterized by a larger precipitation range than 2015 specially during the first months of each year (INIA, 2017).

\section{Conclusions}

A sensitive methodology for the underivatized analysis of amino acids in mandarins was developed and applied to the extraction and determination of nine amino acids: asparagine, glutamic acid, glutamine, histidine, methionine, phenylalanine, proline, threonine and tyrosine.

Fifty-nine mandarin samples were analyzed, and the results showed the differences between the amino acid profiles which allow to differentiate the varieties. The most abundant amino acid of each variety was the same in both harvests, however, it was observed that there were significant differences in the concentrations of amino acids between the two years. These differences were also observed when comparing the evolution of the amino acid profiles of cultivar Page upon maturation. The increase in sugar concentration dropped down the proline levels. The results could be explained by the genetic differences between the varieties, as well as due to the environmental conditions. Osmoprotectants as proline showed lower levels in the rainy year 2016 (Zulfiqar et al., 2020).

The analysis of the main amino acids profile in different mandarin varieties using targeted MRM determination by LC-MS/MS proved to be a straightforward methodology to broaden marketing opportunities for the citrus industry, giving emphasis to the health-promoting effects of mandarins consumption due to their amino acids composition.

\section{Authors' contribution}

Conceptualization: Heinzen, H.; Besil, N.

Data curation: Not applicable

Formal Analysis: Rezende, S.; Migues, I.; Banchero, S.

Funding acquisition: Not applicable

Investigation: Not applicable

Methodology: Rezende, S.; Migues, I.; Banchero, S.

Project Administration: Rivas, C. F.; Heinzen, H.

Resources: Rivas, C. F.
Software: Not applicable

Supervision: Cesio, M. V.; Besil, N.

Validation: Rezende, S.; Migues, I.; Banchero, S.

Visualization: Not applicable

Writing - original draft: Rezende, S.; Migues, I.

Writing - review \& editing: Cesio, M. V.; Heinzen, H.; Besil, N.

\section{Data availability statement}

The data will be available upon request.

\section{Funding}

Financial support from INIA through the L4 funding program, the Agencia Nacional de Investigación e Innovación (award POS_NAC_2017_1_140316) and the Programa de Desarrollo de las Ciencias Básicas (PEDECIBA).

\section{Acknowledgments}

The authors want to thank Joanna Lado (INIA) for her participation during mandarin cultivars sampling. Rezende and Banchero are grateful to Departamento de Química del Litoral for the possibility of performing their undergraduate thesis.

\section{References}

Alterman, M. A.; Hunziker, P. Amino Acid Analysis: Methods and Protocols; Springer, 2012. https://doi.org/10.1007/978-1-61779-445-2

Bringans, S.; Stoll, T.; Winfield, K.; Casey, T.; Davis, T.; Albanese, J.; Lipscombe, R. Protein Biomarker Research Pipeline for Developing Protein Biomarkers for Diabetic Kidney Disease. $A B$ Sciex, 2011, 1-5. http://www.proteomics.com.au/wp-

content/uploads/Biomarker-Pipeline-Diabetes-4250211-

01.pdf (accessed 2020-06-10).

Cupisti, A.; Bolasco, P. Keto-analogues and essential aminoacids and other supplements in the conservative management of chronic kidney disease. Panminerva Med. 2017, 59 (2), 149-156. https://doi.org/10.23736/S00310808.16.03288-2

Chong, J.; Soufan, O.; Li, C.; Caraus, I.; Li, S.; Bourque, G.; Wishart, D. S.; Xia, J. MetaboAnalyst 4.0: Towards more transparent and integrative metabolomics analysis. Nucleic Acids Res. 2018, $46 \quad$ (W1), W486-W494. https://doi.org/10.1093/nar/gky310 
Chong, J.; Xia, J. MetaboAnalystR: An R package for flexible and reproducible analysis of metabolomics data. Bioinformatics 2018, $34 \quad$ (24), 4313-4314. https://doi.org/10.1093/bioinformatics/bty528

Dewick, P. M. Medicinal Natural Products: A Biosynthetic Approach; Wiley \& Sons, 2009. https://doi.org/10.1002/9780470742761

EU Reference Laboratories for Residues of Pesticides (EURL). Analytical quality control and method validation procedures for pesticide residues analysis in food and feed; SANTE/2017/11813; European Commission: Brussels, 2017. https://www.eurlpesticides.eu/userfiles/file/EurlALL/SANTE_11813_2017fin.pdf (accessed 2020-06-11).

Fernández, E. L. Alimentos funcionales y nutracéuticos; Sociedad Española de Cardiología, 2007.

Haleem, D. J. Improving Therapeutics in Anorexia Nervosa with Tryptophan. Life Sci. 2017, 178, 87-93. https://doi.org/10.1016/j.lfs.2017.04.015

Instituto Nacional de Investigación Agropecuaria (INIA). Estación meteorológica. 2017. http://www.inia.uy/gras/Clima/Precipitaciónnacional/Estación-meteorológica (accessed April 2017).

Kefford, J. F.; Chandler, B. V. The Chemical Constituents of Citrus Fruits; Academic Press, 1970.

Khan, M. K.; Zill-E-Huma; Dangles, O. A Comprehensive review on flavanones, the major citrus polyphenols. J. Food Compost. Anal. 2014, 33 (1), 85-104. https://doi.org/10.1016/j.jfca.2013.11.004

Killiny, N.; Hijaz, F. Amino acids implicated in plant defense are higher in Candidatus liberibacter asiaticustolerant citrus varieties. Plant Signal. Behav. 2016, 11 (4), e1171449. https://doi.org/10.1080/15592324.2016.1171449

Ladanyia, M. Citrus Fruit: Biology, Technology and Evaluation; Academic Press, 2008.

Lado, J.; Gambetta, G.; Zacarias, L. Key Determinants of Citrus Fruit Quality: Metabolites and Main Changes during Maturation. Sci. Hortic. 2018, 233, 238-248. https://doi.org/10.1016/j.scienta.2018.01.055

Lin, Q.; Wang, C.; Dong, W.; Jiang, Q.; Wang, D.; Li, S.; Chen, M.; Liu, C.; Sun, C.; Chen, K. Transcriptome and metabolome analyses of sugar and organic acid metabolism in Ponkan (Citrus reticulata) fruit during fruit maturation. Gene 2015, $554 \quad$ (1), 64-74. https://doi.org/10.1016/j.gene.2014.10.025

Migues, I.; Hodos, N.; Moltini, A. I.; Gámbaro, A.; Rivas, F.; Moyna, G.; Heinzen, H. ${ }^{1} \mathrm{H}$ NMR metabolic profiles as selection tools of new mandarin cultivars based on fruit acceptability. Sci. Hortic. 2021, 287, 110262. https://doi.org/10.1016/j.scienta.2021.110262

Otero, A.; Grasso, R.; Goñi, C.; Pérez, E.; Rubio, L.; Maeso, D.; Bertalmío, A.; Buenahora, J.; Giambiasi, M.; Arruabarrena, A.; Lado, J.; Moltini, A. I.; Fasiolo, C.; Espino, M.; Rivas, F. Desafíos de la citricultura en el uruguay y el aporte de inia a su competitividad. Revista INIA 2020, 61, 55-68.

Piraud, M.; Vianey-Saban, C.; Petritis, K.; Elfakir, C.; Steghens, J.-P.; Morla, A.; Bouchu, D. ESI-MS/MS analysis of underivatised amino acids: a new tool for the diagnosis of inherited disorders of amino acid metabolism. Fragmentation study of 79 molecules of biological interest in positive and negative ionisation mode. Rapid Commun. Mass Spectrom. 2003, 17 (12), 1297-1311. https://doi.org/10.1002/rcm.1054

Sadka, A.; Shlizerman, L.; Kamara, I.; Blumwald, E. Primary Metabolism in Citrus Fruit as Affected by Its Unique Structure. Front. Plant Sci. 2019, 10, 1167. https://doi.org/10.3389/fpls.2019.01167

Sharma, V.; Singh, L.; Verma, N.; Kalra, G. The Nutraceutical Amino Acids: Nature's Fortification for Robust Health. Br. J. Pharm. Res. 2016, 11 (3), 1-20. https://doi.org/10.9734/BJPR/2016/24415

Torres, G. A. M.; Gimenes, M. A.; Rosa Junior, V. E., Quecini, V. Identifying water stress-response mechanisms in citrus by in silico transcriptome analysis. Genet. Mol. Biol. 2007, $30 \quad$ (3 $\quad$ Suppl.), 888-905. https://doi.org/10.1590/S1415-47572007000500018

Underwood, J. C.; Rockland, L. B. Nitrogenous constituents in citrus fruits. J. Food Sci. 1953, 18 (1-6), 17-29. https://doi.org/10.1111/j.1365-2621.1953.tb17681.x

van den Berg, R. A.; Hoefsloot, H. C. J.; Westerhuis, J. A.; Smilde, A. K.; van der Werf, M. J. Centering, scaling, and transformations: improving the biological information content of metabolomics data. BMC Genomics 2006, 7, 142. https://doi.org/10.1186/1471-2164-7-142

Verpoorte, R.; Choi, Y. H.; Kim, H. K. NMR-based metabolomics at work in phytochemistry. Phytochem. Rev. 2007, 6, 3-14. https://doi.org/10.1007/s11101-006-9031-3

Wright, M. J.; Thomas, R. L.; Stanford, P. E.; Horvath, A. R. Multiple Reaction Monitoring with Multistage Fragmentation (MRM3) Detection Enhances Selectivity for LC-MS/MS Analysis of Plasma Free Metanephrines. Clin. $\begin{array}{lllll}\text { Chem. } & 2015, & 61 & \text { (3), } & \text { 505-513. }\end{array}$ https://doi.org/10.1373/clinchem.2014.233551

Xi, W.; Fang, B.; Zhao, Q.; Jiao, B.; Zhou, Z. Flavonoid composition and antioxidant activities of Chinese local pummelo (Citrus Grandis Osbeck.) varieties. Food Chem. 
2014,

161,

230-238.

https://doi.org/10.1016/j.foodchem.2014.04.001

Yao, X.; Zhou, G.; Tang, Y.; Pang, H.; Qian, Y.; Guo, S.; Mo, X.; Zhu, S.; Su, S.; Qian, D.; Jin, C.; Qin, Y.; Duan, J.a. Direct determination of underivatized amino acids from Ginkgo biloba leaves by using hydrophilic interaction ultrahigh performance liquid chromatography coupled with triple quadrupole mass spectrometry. J. Sep. Sci. 2013, 36 (17), 2878-2887. https://doi.org/10.1002/jssc.201201045

Zulfiqar, F.; Akram, N. A.; Ashra, M. Osmoprotection in plants under abiotic stresses: new insights into a classical phenomenon. Planta 2020, 251, 3. https://doi.org/10.1007/s00425-019-03293-1 